\title{
Processos Rituais e Homossexualidades: Culturas, Territórios e Representações
}

\author{
Ritual Processes and Homosexualities: Cultures, Territories and Representations
}

\author{
Guilherme Rodrigues Passamani \\ Universidade Federal de Mato Grosso do Sul \\ grpsociais@hotmail.com
}

\begin{abstract}
Resumo
As pesquisas em Ciências Sociais congregam uma diversidade muito grande de temáticas. Desde o fenômeno AIDS, princípio da década de oitenta do Século XX, este ramo do conhecimento voltou sua atenção mais efetiva para a problemática que envolve as sexualidades, com amplo destaque para os estudos sobre as homossexualidades. Este artigo, assim, põe em diálogo uma área já clássica nas Ciências Sociais - que são os estudos de rituais com um tema emergente neste universo - as homossexualidades. No entanto, a partir de alguns estudos pode-se perceber que as práticas homossexuais, enquanto processos rituais, são situações correntes em diferentes culturas e territórios, conferindo representações sociais que ajudam a organizar estas sociedades.
\end{abstract}

Palavras-chave: Rituais, homossexualidades, vulturas

\begin{abstract}
The researches in Social Sciences congregate a very wide diversity of topics. Since the Aids phenomenon, in the beginning of the eighties of the twentieth century, this area of knowledge turns its attention more effectively to the issues that involve the sexualities, emphasizing the studies about homosexualities. So, this article puts into dialogue a classic area in Social Sciences - the studies of rituals - with an emergent topic in this universe - the homosexualities. However, from some studies, it seems possible to realize that the homosexual practices, as a ritual process, are current situations in different cultures and territories, providing social representations that help to organize these societies.
\end{abstract}

Keywords: Rituals; homosexualities; cultures 


\section{Introdução}

Este artigo faz parte de uma discussão mais ampla que estou fazendo em virtude da preparação de um livro que problematizará as questões de homossexualidades, rituais contemporâneos em sociedades complexas e a pesquisa antropológica.

Aqui, estou pensando em rituais que envolvem as práticas homossexuais entre homens, em diferentes momentos históricos e em comunidades humanas distintas. Isto poderia dar a entender que eu compreendo as homossexualidades como um fenômeno trans histórico.

Tenho, pois, outra percepção acerca do fato. Diferente de antropólogos como, por exemplo, de Luiz Mott, não vejo as homossexualidades como um fenômeno recorrente na história da humanidade, o que eu percebo como passível de reiteradas críticas. Mott parte das 12 tribos de Israel, no tempo de Abraão, onde, segundo ele, já existia homossexualidade e homofobia (2006, p.42).

Parece-me claro, e acredito que a todas as pessoas que exercitam alguma criticidade diante das religiões messiânicas, que a diversidade sexual é um elemento fisiológico dos animais em geral. Entre eles, os humanos. Isto é, as práticas sexuais entre iguais e diferentes é um fenômeno histórico, este sim. Porque envolve um misto de necessidade, prazer e perpetuação da espécie.

No entanto, essa constatação é muito distinta ao dizer que as homossexualidades sempre existiram. Não vejo nas práticas homossexuais entre aqueles que foram apedrejados pelos mandamentos da Lei Judaica, qualquer indício de uma identidade homossexual, senão práticas casuais.

As homossexualidades, enquanto identidades ou práticas identitárias que singularizam um indivíduo, como já observara Foucault (1988), datam do século XIX, quando esta forma de expressão da sexualidade passa a ser patologizada e isolada pela medicina da época.

O que Mott vê como demonstração de homossexualidades na antiguidade, eu diria que são exemplos de práticas sexuais não ortodoxas entre iguais, mas que não conferem a insígnia 'homossexual' a qualquer dos envolvidos. Isto não é um fenômeno da antiguidade. Os rituais onde as práticas homossexuais, ou contemporaneamente, as homossexualidades estão em um lugar de destaque, igualmente não são fenômenos isolados das sociedades complexas do Ocidente.

Em vista disso, é que este artigo recupera alguns casos de práticas homossexuais em algumas comunidades humanas, onde a ideia de homossexualidade não existia, ou em caso de existência, estava momentaneamente destituída dos juízos pejorativos de valor que ainda hoje é de convívio constante para a população LGBT.

Para tentar dar conta do debate, parto das teorias sobre ritos e rituais na Antropologia e nas Ciências Sociais, para entender como os teóricos estão pensando a questão e como eles edificam essa temática como uma área profícua de interesse acadêmico no seio de nossas disciplinas.

Em um segundo momento, a discussão centra-se nos processos rituais de diferentes comunidades culturais, via de regra, pensando a iniciação do jovem do sexo masculino no mundo adulto. Situação esta permeada, em algum momento, pela inserção do mundo dos jogos sexuais e eróticos com uma outra pessoa de seu mesmo sexo biológico.

Por fim, permito-me pensar a questão de ritos e rituais, que aqui chamo de homossexuais, em três momentos e territórios distintos na sociedade brasileira. Primeiro, entre os índios Nambiquara - nos anos trinta do Século XX; depois entre os pais-desanto nos cultos afro-brasileiros no norte do país; e por último, entre detentos de uma penitenciária do sudeste. Em todos estes casos, as práticas sexuais ou a sexualidade dos indivíduos é central para compreender distintos momentos de sua prática social cotidiana.

\section{Os Rituais Segundo as Ciências Sociais}

Existe há mais de um século uma discussão considerável nas Ciências Sociais sobre os rituais. Essa discussão já fazia parte, inclusive, das abordagens dos pioneiros da disciplina. A problematização de ritos e rituais adentra as Ciências Sociais como resultado de análises no campo religioso e está presente nos principais estudos das escolas francesa e inglesa de Antropologia.

Em uma passagem de Mariza Peirano, contemporânea antropóloga brasileira, no livro 'O Dito e o Feito - Ensaios de Antropologia dos Rituais (2001)', ela adverte:

(...) não compete aos antropólogos definir o que são rituais. "Rituais", "eventos especiais", "eventos comunicativos" ou "eventos críticos" são demarcados em termos etnográficos e sua definição só pode ser relativa - nunca absoluta ou a priori; ao pesquisador cabe apenas a sensibilidade de detectar o que são, e quais são, os eventos especiais para os nativos (sejam "nativos" políticos, o cidadão comum, ou até cientistas sociais) (PEIRANO, 2001, p. 09). 
Temos a expectativa, também como Peirano, de que os ritos (não definidos pelos antropólogos, mas pelos próprios sujeitos) continuam sendo uma espécie de resposta às representações, todavia adornados por uma dimensão 'imponderável', este aspecto tão inusitado quanto fundamental que articula as relações entre as pessoas na vida social.

Com a modernização das sociedades, desenvolvimento e abrangência dos universos de pesquisa, os estudos de rituais também tiveram alterados os seus contextos. Deixa-se apenas o domínio das sociedades ditas primitivas e tradicionais e começa-se a analisar rituais nas sociedades complexas e contemporâneas, o que determina uma diversidade enorme de possibilidades de investigação, uma vez que toda e qualquer sociedade organiza-se e mantém-se a partir de símbolos e representações.

Já no final do século XIX, Sir James Frazer, em 'O Ramo de Ouro', aventurava-se pelo universo dos rituais e estabelecia uma série de classificações dos ritos. Porém, sem dúvidas, os trabalhos de maior impacto acerca desta temática, no período, foram os de Ėmile Durkheim, que reserva espaço considerável em suas produções para o tema de ritos e rituais, quase sempre ligados à religião. Martine Segalen (2002), comparando Frazer e Durkheim, adverte-nos de que:

Sir James Frazer apresentava as crenças e as magias do mundo como fatos de superstição, signos que testemunhavam o espírito infantil dos indígenas, sua irracionalidade e o espírito pré-lógico. Durkheim, ao contrário, leva todos esses fatos a sério, atribuindo-os à categoria religiosa (SEGALEN, 2002, p. 19).

O que Segalen acentua é a proposta de Durkheim de estudar a religião totêmica entre os aborígines da Austrália e indígenas da América do Norte, na expectativa de poder encontrar, naquelas sociedades 'simples', princípios estruturais capazes de permitir a análise de toda e qualquer forma de religiosidade (distinção entre sagrado e profano e ritos positivos e negativos), inclusive as formas presentes nas sociedades 'complexas'.

Segalen analisa a obra de Mary Douglas e seus testes para verificar a eficácia dos rituais. Para Douglas, o rito deveria ser encarado como uma ação tradicional efica, ou seja, seu desdobramento apresenta um resultado e um sentido para os seus participantes. Logo, o rito existe na medida em que produz sentido para alguma coisa. Mary Douglas, frequentemente, estabelece rito como sinônimo de símbolo (Idem. p. 29).
Corroborando estas ideias, temos, em Mariza Peirano, uma referência importante aos trabalhos de Lèvi-Strauss que, embora questionando o totemismo como instituição e conferindo a ele o lugar de mecanismo de articulação do pensamento, não conseguiu desfazer-se e mais, defendeu a manutenção das dicotomias que separam mitos e ritos. Aos mitos continuava-se a delegar o caminho de acesso ao pensamento. Já os ritos encarregavam-se de uma dimensão mais prática da vida. Lèvi-Strauss encarrega-se de separar estes dois universos. Mitos associam-se às representações. Ritos a relações sociais empíricas (PEIRANO, 2001).

Merece destaque a obra de Arnold Van Gennep que, em 'Os Ritos de Passagem (1977)', lançado em 1908, tornou-se um dos primeiros estudiosos a problematizar os ritos como espaços independentes. A obra de Van Gennep evidentemente é datada e hoje recebe algumas críticas por se tratar de uma pesquisa muito generalista e pouco profunda, mas, inegavelmente, tem todos os méritos por ter sido um trabalho pioneiro e desbravador.

Van Gennep, em suas pesquisas com diversas sociedades, conseguiu perceber que a ideia de totalidade amorfa aplicada aos agrupamentos humanos de forma geral, não se sustenta quando o olhar é refinado e enfocado, pois, como ele observara, uma sociedade geral é composta por várias sociedades especiais, menores, porém, igualmente, complexas. Nesse sentido, Van Gennep corrobora a tese hodiernamente hegemônica no universo da Antropologia - de que o relativismo é a melhor forma de compreender sociedades, culturas e pessoas (VAN GENNEP, 1977).

Outro ponto básico, mas que na época do autor fora uma grande descoberta, é o de que em algumas fases da vida, ou em momentos especiais, para que se passe de fase a fase, ou para uma realidade distinta, são necessários ritos de passagem, ou seja, "cerimônias, atos de um gênero especial, ligados a uma certa tendência de sensibilidade e a determinada orientação mental" (Idem. p. 25). Essas cerimônias ocorrem para ambos os sexos, nas diferentes classes sociais e, provavelmente, em todas as culturas humanas. Nas diferentes culturas, diferentes rituais e diferentes significados serão aplicados a estes momentos.

Van Gennep estuda ritos de iniciação em diferentes sociedades. O que chama atenção é que muitos destes rituais são direcionados para rapazes, geralmente, na época da puberdade e tais cerimônias serviriam para introduzir o rapaz no mundo adulto. A puberdade é reconhecida não tanto pela idade cronológica, mas pelo aparecimento de pelos na região pubiana, bem como, pelo nascimento de barba e as primeiras 
emissões de muco e esperma. A introdução no mundo adulto pode significar, por exemplo, a introdução não apenas no mundo da sexualidade, como também no mundo do trabalho e na participação da gestão da vida daquele grupo (Ibidem. p.72).

Roberto DaMatta mostra que os ritos não devem ser vistos como mecanismos capazes ou encarregados de resolver os problemas humanos, mas eles são um combustível fundamental para organização e sequência das sociedades de forma consciente. Os ritos, através desta ótica, podem ter inclusive funções dicotômicas, mas estão a acompanhar as recorrentes transformações que se operam no mundo social. Portanto, o rito é "elemento crítico da vida social humana" (DAMATTA, 1977, p. 13).

Para DaMatta, Van Gennep estuda os ritos como fenômenos compartimentalizados, numa espécie da casa social, onde os ritos mostrariam as possibilidades de passear por seus corredores, salas e quartos, construindo seus caminhos sociais. Além disso, o estudioso entende que o rito não se explica pela busca de uma essência social, senão por seu aspecto relativo diante de contextos específicos de relações sociais.

A crítica principal, que recai a Van Gennep, é sua opção pela quantidade em vista da qualidade. Ele preferiu mapear um número enorme de ritos, mas não conseguiu aprofundar-se em quase nenhum. Isto implica uma ausência clara de Gennep sobre o que seriam, concreta e teoricamente, 'os ritos de passagem.'

No entanto, seus estudos pioneiros serviram de base para o estudo dos rituais. Este é o caso, por exemplo, de Victor Turner, cujo trabalho mais destacado, 'O Processo Ritual - Estrutura e Antiestrutura (1974)' vale-se do que Gennep chamou de fase 'liminar' dos ritos de passagem. Turner seguiu as ideias de Van Gennep, que via nos ritos de passagem uma mudança de lugar, de posição social e de idade. Ele deteve-se nesta segunda fase dos ritos, a liminaridade, onde "as características do sujeito ritual (o 'transitante') são ambíguas; passa através de um domínio cultural que têm poucos, ou quase nenhum dos atributos do passado ou do futuro" (TURNER, 1974, p. 117).

Para o autor, as pessoas que estão vivendo a liminaridade furtam-se ou escapam a uma rede coerente de classificação, a qual normalmente estaria encarregada de determinar a localização de estados e posições em dado espaço cultural. Portanto, a liminaridade apresenta-se como um não lugar, isto é, estão no vácuo das posições atribuídas ou ordenadas pela lei, pelos hábitos e costumes, bem como pelas convenções sociais e cerimônias comuns. Neste sentido, inclusive, poderíamos aferir que estes seres liminares, segundo Turner, não possuem qualquer status diante da sociedade durante toda esta fase (Idem. p.117).

Nos fenômenos liminares, os sentimentos e as identidades encontram-se com suas fronteiras muito borradas. Durante esse período, surge uma sociedade do tipo communitas, que se caracteriza por ser uma organização não estruturada, trata-se de uma comunhão de indivíduos semelhantes, cujas realidades nesse ínterim os submetem, em conjunto, às autoridades rituais. Desta forma, toda a hierarquia do ritual é interdependente. Aqueles que estão em posições privilegiadas, só estão lá porque outrora passaram pelos ritos de separação, pela liminaridade até que alcançassem este status.

Turner percebe que o indivíduo que se encontra na liminaridade está despossuído, como vimos, de qualquer status social, todavia no desenrolar do ritual este subordinado torna-se a figura central, pois o rito ocorre em virtude dele. Por esta razão, durante a fase da liminaridade, este sujeito precisa comportar-se como uma tábua rasa, isto é, estar livre de tudo juízos morais, valores, verdades, definições - para que possa ser inscrito, por meio do ritual, em sua nova pessoa social o conhecimento, a sabedoria, as regras e as verdades que são compartilhadas e dão sentido ao grupo do qual ele começa a fazer parte a partir do novo status (TURNER, 1974).

Frisa-se que a communitas tem lugar no processo ritual na fase da liminaridade, isto é, nas bordas da estrutura social. Pode-se compreender que ela é uma fase marginal, está sob a estrutura, trata-se de uma condição de inferioridade diante da norma estrutural. A communitas é um fenômeno que transcende, muito embora seja resultado das faculdades humanas, da racionalidade principalmente. Assim, ela funciona como uma dimensão intermediária para aqueles que saíram da estrutura, estão na liminaridade, investindose dos subsídios rituais, para voltarem à estrutura em um outro lugar.

Uma abordagem muito revisitada na Antropologia é a de Stanley Tambiah. Segundo Mariza Peirano, Tambiah não define ritual em termos absolutos. Ele entendia que "os eventos que os antropólogos definem como rituais parecem partilhar alguns traços: uma ordenação que os estrutura, um sentido de realização coletiva com propósito definido e também uma percepção de que eles são diferentes dos do cotidiano" (PEIRANO, 2001, p. 25). A partir desta lógica, ainda que os rituais compartilhem alguns traços comuns, eles variam conforme pressupostos ideológicos específicos. Tambiah compreende assim que mesmo no interior de uma comunidade específica, não se pode falar em homogeneidade, por exemplo, em vista de mesmo entre os segmentos dessa comunidade existem 
interesses ideológicos distintos.

Nas ditas sociedades complexas, por exemplo, as pessoas agem segundo seu livre arbítrio, ou seja, a moral coletiva tem um peso em suas decisões, mas não as molda de forma a retirar sua capacidade individual de escolha. Por outro lado, as sociedades tradicionais estabelecem as 'representações coletivas' como sobrepujantes diante do sujeito individual. Ele opera apenas como uma manifestação ou depositário da vontade coletiva. Neste sentido, sua capacidade individual de articular e decidir soterra-se diante do todo.

\section{As Práticas (Homos)Sexuais como Processos Rituais em Diferentes Culturas}

O interesse teórico das Ciências Sociais pelo mundo dos rituais foi marcado a partir de diversas experiências concretas com estes fenômenos em distintas sociedades ao redor do mundo. Para este artigo, pretendo fazer uma rápida abordagem de rituais que envolvem práticas sexuais entre indivíduos de um mesmo sexo biológico, sem implicar, necessariamente, na adoção da homossexualidade como expressão de sua sexualidade.

Não se pode negligenciar, por exemplo, o caso das iniciações sexuais na Grécia Clássica. Nos tradicionais banquetes, onde mais do que os melhores vinhos e as discussões filosóficas mais apuradas havia uma parte muito interessante e tão pouco debatida, que era as relações sexuais entre os homens, sim, porque se tratava de um espaço genuinamente masculino, com raríssimas exceções, uma vez que a cidadania grega passava por ser pertencente ao sexo masculino.

Neste espaço de homens livres e dados aos mais altos debates acerca do conhecimento, entendia-se que o saber só poderia ser transmitido entre iguais, entre aqueles que detinham as condições apropriadas a determinados entendimentos. Portanto, o amor verdadeiro, aquele sentimento mais nobre e mais libertador, só poderia ser exercido e vivenciado pelos iguais. Isto se traduzia em uma relação de afeto que poderia durar anos. Especula-se que os mais prestigiados filósofos, por exemplo, colecionaram - ao longo da vida - inúmeros mancebos.

Neste sentido, os gregos clássicos viam, nas relações sexuais entre homens, um momento privilegiado de transmissão de conhecimento, ou seja, o líquido precioso repassado corpo-a-corpo era uma materialização da verdade difundida através do sexo. As relações sexuais davam-se sempre entre homens de diferentes faixas etárias. O homem mais velho era o ativo na relação (erasta) e um jovem que se iniciava na vida adulta e no mundo do conhecimento (erômero), na função passiva (FOUCAULT, 1988).

Os iguais, em matéria de sexo fisiológico, eram vistos socialmente como diferentes e, portanto, esta relação não sofria qualquer sanção por parte da sociedade da época. Ambos resguardavam suas personalidades masculinas diante da sociedade após estes rituais de transmissão de conhecimento. Fato que não era comum àqueles homens afeminados e que se ofereciam aos outros nos banquetes, bem como àqueles que mantinham relações sexuais e pertenciam a uma mesma faixa etária. Tais sujeitos eram vítimas de preconceito e descriminação, pois burlavam as rígidas leis do permitido.

Peter Fry e Edward MacRae em um livro introdutório, mas clássico nos estudos de homossexualidades no Brasil, 'O que é homossexualidade' (1985), destacam casos de incorporação das homossexualidades à vida das comunidades locais sem maiores traumas, tabus ou discriminação. Não são poucas às vezes em que estas sexualidades adentram a vida destes grupos a partir de distintos processos rituais.

Um caso relatado por Fry e MacRae é o dos índios Guaiqui do Paraguai. Entre esta população, a divisão do trabalho envolvia funções diferentes para homens e mulheres. Os homens caçavam. $\mathrm{E}$ as mulheres colhiam. Portanto, homens usavam arcos e as mulheres utilizavam as cestas. Eram mundos distintos. Por trás deles estavam os princípios de masculinidade e feminilidade.

Dois casos são apontados: Chachu era um índio viúvo que não conseguia caçar. Era excluído do mundo masculino. Dessa forma, pegava uma cesta e ia fazer a coleta com as mulheres. Era razão de escárnio da tribo, pois burlava os limites entre os mundos feminino e masculino. Era um homem no mundo das mulheres. Tornava-se menos homem.

Por outro lado, Clastres, que estudou estes índios, elenca o caso de Krembégi que também não caçava, mas resolveu inserir-se de maneira total no universo feminino da tribo. Deixou os cabelos crescerem e aderiu a todas as atividades das mulheres, incluindo a coleta. Krembégi até mesmo envolvia-se sexualmente com os homens da tribo, de forma passiva. Ele não fora excluído, como o primeiro. Pois era visto pelos demais como uma mulher, ou melhor, como um kyrypy-meno (ânus de fazer amor).

Os Guaiqui, dessa forma, nos demonstram que, entre eles, as masculinidades envolvem a habilidade da caça e o papel 'ativo' nas relações sexuais. Qualquer destas ausências insere o indivíduo no mundo antagônico, ou seja, o feminino. E cabe a este indivíduo uma adesão total a este mundo. Anulando-se 
como homem a fim de que não sofra sanções ou escárnios (FRY, MACRAE, 1985).

Segundo Peter Fry e Edward MacRae (1985), nas tribos da América do Norte, essas situações também não são incomuns. Entre os Kutenai, no Canadá, era muito possível esta 'transformação' de homens em mulheres e de mulheres em homens. Inclusive, estes rituais poderiam resultar em casamento. Os 'transformados' eram chamados de berdaches $\mathrm{e}$ recebiam poderes curativos e proféticos. Não eram discriminados em suas tribos e, até mesmo, recebiam algum destaque em vista dos poderes que detinham.

Jurandir Freire Costa (1996) mostra a relação de culturas locais com a sexualidade em geral e com as homossexualidades especificamente. Costa se vale do estudo de Herdt e Stoller acerca da tribo Sambia, da Nova Guiné. Nesta comunidade, em se tratando de sexualidade, o fundamental é a relação das pessoas com o esperma, reconhecidamente escasso e capaz de perpetuar a vida.

A relação de proximidade com o esperma é o que determina a moralidade nas práticas sexuais. Eles entendem o esperma como o princípio da vida. Todas as pessoas da tribo têm uma relação muito próxima com o esperma. As noções ocidentais de homossexualidade e heterossexualidade inexistem. Jurandir Freira Costa (1996) mostra que para o povo Sambia a relação sexual mais importante é a felação. O sêmen precisa circular entre as pessoas, a fim de que espalhe a vida.

O que nós entendemos como relações homossexuais faz parte de um ritual de iniciação dos meninos Sambia, com destaque para a felação do jovem no adulto. Neste sentido, o menino que faz a felação adquirirá força, crescerá e será um bom produtor de esperma ao longo da vida, garantindo mais uma geração de Sambia. Todos os meninos desta etnia passam por esse mesmo processo, pois se entende que apenas desta forma eles estarão preparando-se de forma completa para a vida adulta. Trata-se de um olhar completamente diferente do nosso para a questão e confere sentido para a vida da tribo, naquela e nas próximas gerações.

Dennis Wernner (1987), na esteira destes autores, também relata uma série de experiências sexuais entre iguais em diferentes culturas humanas, onde os ideais e as moralidades têm uma visão um pouco mais alargada que em nossa cultura ocidental contemporânea. Tais relatos mostram como a moral e a cultura são elementos complexos e variantes, pois o que é absolutamente imoral para muitos de nós, pode ser a regra para uma dada sociedade.

Entre caçadores e coletores da Austrália Central, Wernner destaca que todas as relações sexuais entre pessoas do mesmo sexo operam segundo um ritual. Nos rituais, há uma marcada diferença de idade e geralmente ocorrem em um momento-chave da vida dos iniciados, ou seja, os meninos jovens que experimentam a relação como um processo pelos quais devem passar, a fim de transformarem-se em 'homens de verdade ${ }^{\prime 1}$ :

Entre os Aranda, caçadores e coletores da Austrália Central, os homens adotam como "mulher" rapazes não-iniciados de dez a doze anos, e praticam sexo com eles. (...) $\mathrm{Na}$ sociedade Kaluli da Nova Guiné, os pais escolhem um homem saudável para ter relações sexuais durante vários meses com os seus filhos de onze a doze anos. Esse sexo é considerado necessário ao desenvolvimento do rapaz (WERNNER, 1987, p. 99).

Aos olhos da nossa cultura, estamos diante de fatos concretos que envolvem pedofilia e, logo, diante de criminosos. Porém, a diversidade cultural estabelece que esse ritual durante a pré-adolescência do menino será importante no sentido de capacitá-lo para a vida adulta e trata-se de um processo que ocorre a várias gerações e ao qual o seu pai e parentes da linhagem masculina, invariavelmente, submeteram-se, sem comprometer o seu papel masculino diante da sociedade.

Entre os Etóro, da Nova Guiné, merece destaque o ritual da inseminação. Este ritual envolvia a prática homossexual entre um homem mais velho e um rapaz. Tais relações dão-se por meio da felação, uma vez que o rapaz precisa ingerir oralmente o esperma. Este ritual contribuiria para a saúde do jovem, bem como garantiria boas colheitas e caças abundantes. Os jovens estariam sujeitos a tais rituais entre os dez e os vinte e cinco anos. Um detalhe curioso é que esta tribo abominava o sexo anal entre pessoas do mesmo sexo biológico. Também, tinha muitas restrições ao sexo heterossexual, que se mantinha proibido por um período que variava de 205 a 260 dias por ano. Eles entendiam que a grande frequência sexual era nefasta para as plantas e para as trocas econômicas (Idem. 1987).

Outros tantos exemplos poderiam ser dados, a fim de corroborar a ideia de que as práticas homossexuais adentram diversas sociedades através de rituais que são absorvidos pela comunidade e naturalizados. Wernner ainda problematiza o caso dos Azande, do Sudão; os Usbecos e Tajicos de Aq Kupruk, no Afeganistão; os Crow e Koniag, dos Estados Unidos. Mas sem dúvida, um caso que merece destaque são as 
práticas homossexuais no Japão, do século XVIII, quando aquele território era considerado super povoado. Nesse sentido, os rituais sexuais entre homens eram incentivados e considerados como um "tipo nobre e masculino de expressão amorosa, constituindo-se numa prática comum dos samurais" (WERNNER, 1987, p. 106).

Em todos estes casos, que cobrem diversas regiões do globo, situados historicamente em períodos distintos, pode-se perceber a construção de práticas sexuais por meio de rituais que conferem sentido à vida cotidiana das comunidades envolvidas. Concepções de mundo, distintas das nossas, estão envolvidas em todos estes processos. Sobretudo, quando se fala em sexualidade, um tema até hoje muito difícil de ser discutido na sociedade brasileira, tão marcada por suas heranças cristãs católicas. Esta dificuldade acentua-se quando a discussão se dá com relação às homossexualidades, ainda vistas em algumas regiões do país como uma deformação moral.

O mundo dos rituais sexuais não se esgota neste pequeno número de casos destacados. Estão faltando ainda alguns casos que exemplifiquem como a situação das práticas sexuais entre pessoas do mesmo sexo é vista em algumas regiões e comunidades específicas do Brasil, muito religioso, mas muito sexual e diverso, em igual medida.

Parece de uma ingenuidade atroz, pensar que um país com as dimensões territoriais do Brasil e com uma diversidade cultural e étnica consideráveis, caberia em definições totais e limitadas, em se tratando de relações e práticas sexuais, bem como definições de sexualidade. Até mesmo neste quesito, as perspectivas brasileiras são muito variadas e não cabem em rótulos que limitam e oprimem.

\section{Casos de Rituais (Homos)Sexuais em Distintos Territórios Brasileiros}

Em meados dos anos trinta do Século XX, um grupo de intelectuais europeus, marcadamente franceses, veio para o Brasil fundar a primeira universidade do país, a Universidade de São Paulo (USP). Dentre estes jovens intelectuais, em início de carreira, estava o filósofo Claude Lèvi-Strauss, que dava seus primeiros passos pelo vasto e ainda desconhecido mundo da Antropologia. Diferente dos demais intelectuais que chegavam ao Brasil, LèviStrauss, após cumprir seus trabalhos acadêmicos, começou a excursionar pelo interior do país, sobretudo pelas regiões centro-oeste e norte.

Essas verdadeiras expedições empreendidas pelo jovem antropólogo, tempos depois, serviram de matéria-prima para uma de suas obras clássicas, o livro 'Tristes Trópicos' (1996). Nesse texto, o pesquisador traça um panorama detalhado das pesquisas realizadas no Brasil e da diversidade étnica das comunidades indígenas. O que interessa, para os limites deste artigo, são as observações de Lèvi-Strauss acerca dos Nambiquara que se espalhavam pelos territórios dos atuais estados de Mato Grosso e Rondônia.

Entre estes indígenas havia um ritual peculiar envolvendo as homossexualidades. Nesta comunidade, a poligamia do 'chefe' era permitida, ou seja, trata-se de uma concessão importante que o grupo faz a seu chefe, pois ele encontra-se em uma condição diferenciada em relação aos demais. Com exceção do chefe da tribo, todos os outros estabeleciam uniões monogâmicas (LÉVI-STRAUSS, 1996).

No entanto, como observa o pesquisador, este sistema acarretava a necessidade de alguns arranjos no grupo:

Ao excluir periodicamente as moças do ciclo regular dos casamentos, o chefe provocava um desequilíbrio entre o número de rapazes e de moças em idade matrimonial. Os homens jovens são as principais vítimas dessa situação, e veem-se condenados, seja a ficarem solteiros por vários anos, seja a desposarem viúvas ou velhas repudiadas pelos maridos (LÉVISTRAUSS, 1996, p.296).

Portanto, a prerrogativa poligâmica do chefe da tribo, causava uma disfunção no restante de seus pares e obrigava os jovens a situações extremas, como a solteirice e o casamento com viúvas e mulheres largadas. No entanto, outra saída foi igualmente encontrada pelos Nambiquara para tentar reverter à situação dos rapazes jovens, cujas pretendentes serviam de mulheres para o chefe da tribo. Trata-se do ritual do tamindige kihandige, que Lèvi-Strauss traduziu, segundo interpretações da tribo, como o 'amor-mentira'. Neste sentido, a problemática da falta de esposa para os jovens podia ser resolvida da seguinte maneira:

Os Nambiquara também resolvem o problema de outra forma: pelas relações homossexuais. (...). Essas relações são correntes entre gente jovem e merecem publicidade muito maior do que as relações normais. Os parceiros não se retiram para o mato, como os adultos de sexos opostos. Instalam-se perto de uma fogueira diante do olhar divertido dos vizinhos. $\mathrm{O}$ incidente dá 
lugar a brincadeiras geralmente discretas; são relações consideradas como infantis, e quase ninguém lhes dá atenção (Idem. p. 296).

O ritual do amor-mentira, como se vê, é uma prática corrente entre os jovens nambiquara até que haja uma esposa disponível para eles. Tais práticas amorosas e sexuais não comprometem a sexualidade masculina dos rapazes, pois se entende, na tribo, esta situação como transitória, além de não vista como séria, uma vez que, aos olhos dos demais, são apenas jogos eróticos infantis.

No entanto, não fica claro nas observações de LéviStrauss (1996) - e esta também era uma dúvida sua se os encontros entre os jovens do mesmo sexo encaminhavam-se até o orgasmo, numa nítida alusão de que os jogos eróticos desdobravam-se em relações sexuais, ou ficavam limitados a trocas de carícias e brincadeiras eróticas. O que fica muito claro, porém, é que entre os Nambiquara este ritual não pressupunha que, devido à falta de mulheres para os rapazes, eles deixassem de 'ser homens', ao envolverem-se em uma fase da vida com outros rapazes. A noção de homossexualidade, neste caso, inexistia, não obstante às práticas erótico-sexuais.

É preciso, porém, frisar alguns limites impostos pela tribo para que o ritual do 'amor-mentira' pudesse ocorrer. As relações homossexuais se davam apenas entre adolescentes que fossem primos cruzados. Segundo Lèvi-Strauss, esta seria uma possibilidade, pois um dos primos, em geral, estaria destinado a casar com a irmã do outro que, momentaneamente, estava impedida, em vista de estar servindo de mulher ao chefe. Neste sentido, seu irmão provisoriamente a substituiria nas relações com seu futuro esposo (Ibidem. p.296).

Logo, 'os primos que fazem amor' eram vistos com muita naturalidade entre os indígenas da tribo, pois se sabia que na idade adulta tal situação teria fim e estabelecer-se-ia uma relação monogâmica e entre sexos opostos. Todavia, a relação afetiva muito próxima entre os cunhados seguia pela vida toda, o que fazia não ser incomum nas noites, estes cunhados passearem abraçados - em nítidas demonstrações de carinho e intimidade - diante de todos, sem quaisquer prejuízos a suas masculinidades e sexualidades.

Neste Brasil plural e popular, muitas são as formas de manifestação das sexualidades, tantas quantas podem ser as pensadas por qualquer pessoa. Peter Fry, em 'Para Inglês Ver' (1982), discute algumas temáticas que guardam relação próxima com as homossexualidades e algumas delas envolvem o mundo dos rituais. Neste sentido, é interessante o olhar que o antropólogo dispensa aos rituais afro-brasileiros no norte do Brasil, onde a presença de homossexuais é constante em postos de liderança.

Os cultos afro-brasileiros, ao longo dos tempos, receberam alguns olhares de reprovação diante de um Brasil genuinamente católico, não obstante ao sincretismo religioso que nos é tão peculiar. Seus frequentadores, em grande medida, eram pessoas de baixa renda e, na grande maioria, não brancos. Portanto, estes rituais apresentavam-se como espaços marginais. Estas margens receberam de 'braços abertos' as homossexualidades, sem quaisquer juízos de valor.

Nas religiões de origem africana, os homossexuais encontraram a oportunidade de um contato mais próximo com o sagrado, sem quaisquer sanções em razão de uma sexualidade desviante de suposta norma social vigente. Pelo contrário, como informa Peter Fry, a partir de dados do seu campo e do campo de outros estudiosos (como Ruth Landes, por exemplo), os homossexuais ocupavam lugares prestigiados nas cerimônias:

Landes sustenta a tese de que "tradicionalmente o papel de líder de culto era essencialmente feminino - "só as mulheres podiam cuidar dos deuses" -, e que por essa razão, os únicos homens que poderiam abrir o culto como médiuns eram "os homossexuais que apesar de serem homens, eram femininos". Dessa maneira, eles poderiam desempenhar papéis femininos sob a proteção do culto. Os homossexuais, diz Landes, "querem uma coisa para a qual o candomblé fornece as mais amplas oportunidades: eles querem ser mulheres" (FRY, 1982, p. 60).

Peter Fry toma todo o cuidado ao debater as questões levantadas por Ruth Landes, uma vez que a pesquisadora faz uma análise superficial e generalista, muito envolta em juízos de valor, não raro, repletos de um moralismo beato. Ainda assim, é importante a relação que ela faz entre homossexualidade e feminino, que é bem diferente do ser mulher. Falo de uma sensibilidade, comumente atribuída nesta sociedade às mulheres.

É evidente que a generalização proposta pela pesquisadora e criticada por Fry é tacanha e carece de uma análise mais pormenorizada, talvez assim Ruth Landes percebesse que há uma diversidade enorme dentro da grande categoria homossexual e o 'ser mulher' pode ser uma ambição de uma parcela deste grande grupo, mas não de sua totalidade. 
Por outro lado, é interessantíssima a análise de Peter Fry ao mostrar a figura homossexual, em grande medida afeminada, na condição de 'pai-de-santo' de muitos terreiros, o que demonstra uma abertura destas religiões e, sobretudo, de seus processos rituais, àqueles que nas religiões mais tradicionais enquadravam-se na condição de criminosos, depravados e imorais. É um outro olhar dispensado para a sexualidade e suas manifestações.

Em outra passagem de 'Para Inglês Ver' (1982), Peter Fry elenca a pesquisa de José Ricardo Ramalho, na 'Casa de Detenção de São Paulo', no início dos anos oitenta do século XX. Nesta investigação, os detentos estabelecem uma hierarquia entre as identidades sexuais que são produzidas dentro das penitenciárias. Esta hierarquização obedece a uma trajetória que lembra um processo ritual. Peter fry, assim explica:

(...) cada vez que chega uma nova leva de presos, os mais velhos e experientes, os mais "malandros", escolhem os rapazes mais bonitos como boys. Diz Ramalho: "É grande a disputa por parceiros sexuais e aquele que foi 'conquistado' deve ser respeitado como 'mulher' do preso. (...) $\mathrm{O}$ preso que tem um boy como 'mulher' deve saber como mantê-lo longe das possíveis aproximações dos outros presos" (FRY, 1982, p. 92).

As observações de Peter Fry demonstram uma organização interna de driblar as limitações sexuais impostas pela falta de liberdade. Esta organização, que implica na união sexual entre dois homens, em nenhum momento levanta qualquer dúvida quanto à sexualidade dos dois, ou melhor, ela levanta alguma suspeita sobre aquele que servirá de 'mulher', nunca para o ativo da relação que, pelo contrário, estaria reafirmando a sua masculinidade ao submeter sexualmente o outro. Em troca, este preso mais antigo, compromete-se a proteger o novato, com o qual terá relações sexuais, de qualquer perigo e mais: este novato deverá ser respeitado pelos demais presos como 'coisa' do líder da cela.

Embora os 'boys' que chegavam tivessem poucas alternativas, porque se tratava de uma questão de sobrevivência, eles podiam escolher a que homem mais velho eles serviriam sexualmente, portanto, havia uma disputa entre os veteranos para se sobressair aos olhos dos recém-chegados. Digo que as alternativas eram poucas, porque certamente a possibilidade a ser escolhida seria a de não se relacionar sexualmente com outro homem, em vista de uma heterossexualidade compulsória. Todavia, esta possibilidade inexistia, pois já era uma prática reiterada para os criminosos que chegavam àquela prisão.

Assim, pode-se perceber a partir dos diversos casos como há uma ligação indelével entre o mundo dos rituais, estabelecido na primeira parte do texto, com as práticas culturais de diferentes grupos espalhados pelo Brasil e o mundo, em distintos momentos históricos. Em todos os casos, os processos rituais têm a função de estabelecer certa ordem na comunidade ou grupo, além de serem constituídos de diferentes momentos que colocam os integrantes dos processos das fases de 'liminaridade e communitas', antes da integração total a uma nova realidade.

\section{Considerações Finais}

É cada vez mais comum na Antropologia contemporânea a viagem ao mundo do Outro ser mais curta do ponto de vista geográfico, o que não significa que o universo de estranhamento não seja igualmente denso e rico em detalhes. No entanto, ao analisar seus semelhantes no interior de sua própria 'sociedade complexa', outra vez, o antropólogo precisará de muita habilidade. Agora, exige-se dele o tato de conseguir estranhar aquilo que lhe é bastante familiar.

Esta realidade acompanha, inclusive, o mundo dos ritos e rituais. Os trabalhos de Van Gennep, Turner hoje pareceriam missões impossíveis, até porque do outro lado da rua já está presente um universo de estranhamento bastante rico e diverso. Portanto, há uma vasta gama de rituais contemporâneos, em nossas sociedades complexas, que carecem destaque e investigação.

Longe e perto de casa, aquele que faz Antropologia precisa estar constantemente em tensão com a ideia e a prática da alteridade, uma vez que ininterruptamente o Outro está na cena do antropólogo. Este Outro pode ser a página de uma revista ou jornal, um dado de internet, uma situação, ou pessoas. Entendo que a problematização apresenta-se bem mais delicada quando temos como interlocutores outros seres humanos que partilham a mesma matriz cultural com o pesquisador.

Adentrar ao mundo dos rituais foi um aventurar-se. Trata-se de uma temática cada vez mais estudada pelas Ciências Sociais, discussão esta que está nas bases das primeiras investigações sociológicas de nossos autores mais clássicos. A Antropologia dos Rituais ajudou a pensar as cerimônias e processos destacados a partir de outra lógica, que não aquela moralista e sectária, compulsoriamente heterossexual e heterossexista. Ela foi uma contribuição muito importante para decompor os processos e contextualizar as cerimônias em um universo mais amplo já revisitado com frequência pela 
Disciplina.

A partir do material recolhido, várias questões podem ser levantadas. Mas uma muito interessante não pode ser negligenciada: as categorias sociedades simples e complexas precisam ser problematizadas. Sobretudo no que tange ao olhar destas sociedades diante de alguns fenômenos. As práticas homossexuais, por exemplo. Tão execradas na racional e 'evoluída' sociedade judaico-cristã, mas percebida como um processo banal em dado momento da vida em muitas 'tribos bárbaras'.

Outro ponto que merece destaque, seguindo esta linha de raciocínio, é o dos olhares à questão. Estas, ditas sociedades simples, ensinam o ocidente cristão, racional e crítico sobre ideias básica de pluralidade, diversidade, liberdade, justiça, trabalho e, por fim, felicidade. Ensina a familiarizar o Outro, quando não a desconstruir a ideia de Outro que nós cristalizamos a partir de uma característica (parte) que nós tomamos como representativa de sua totalidade.

As práticas homossexuais e as homossexualidades - podemos afirmar isso não apenas pelos dados que constam neste artigo, mas por uma gama de trabalhos publicados - constituem um grupo humano consideravelmente distinto e plural. Talvez a única semelhança entre este grupo seja a existência de duas genitálias iguais quando da relação sexual. Tudo o que extrapola o ato sexual entre os iguais, é expresso de forma distinta.

Portanto, pensar as homossexualidades como uma coisa só, homogênea e amorfa, é impossível para alguém que tenha um contato ainda que superficial com a temática. Esta ideia de uma homossexualidade homogênea só tem sentido no interior do pensamento homofóbico, pois precisa manter cristalizado um tipo de ideal de homossexual a ser rechaçado em vista de assegurar a hegemonia da heterossexualidade.

Este temática, ainda que tangencial, insere-se como mais uma contribuição, mesmo limitada, para uma discussão maior que é o combate à homofobia. Homofobia esta, que condena ao silêncio, à infelicidade e, por que não, à morte, pessoas que cometeram o crime de desejarem - afetiva e sexualmente - outras pessoas cujo sexo biológico é igual ao seu.

Propor este tipo de debate, resgatando experiências de outros povos que dialogam com a questão sem os ranços interpostos por nossa cultura, é estar ao lado da garantia do respeito aos direitos humanos. E, assim, como pretenso humanista, entendo que produzir conhecimento acadêmico que vá de encontro a estas verdades inventadas é mais do que uma necessidade de adquirir prestígio intelectual, mas um dever de cientista e cidadão.
1 Dennis Wernner vale-se dos dados coletados pelos seguintes pesquisadores: Ford e Beach; Schieffelin; Kelly.

\section{Referências}

DAMATTA, Roberto. "Introdução". In. VAN GENNEP, Arnold. Os ritos de passagem. Petrópolis: Vozes, 1977, p.s/p.

COSTA, Jurandir Freire. "O referente da identidade homossexual". In. PARKER, R.; BARBOSA, R. (Org.). Sexualidades Brasileiras. Rio de Janeiro, Relume Dumará: ABIA. IMS/UERJ, 1996.

FOUCAULT, Michel. História da Sexualidade I. O cuidado de si. Rio de Janeiro: Graal, 1988.

FRY, Peter. Para inglês ver. Rio de Janeiro: Zahar, 1982.

FRY, Peter; MACRAE, Edward. O que é homossexualidade? São Paulo: Brasiliense, 1985.

LÉVI-STRAUSS, Claude. Tristes Trópicos. São Paulo: Companhia das Letras, 1996.

MOTT, Luiz. "Homofobia no Brasil". In. MELLO, Caren. Quando o arco-íris assombra. Arquipélago Revista de livros e ideias. Porto Alegre: IEL, 2006, p.s/p.

PEIRANO, Mariza (Org.). O Dito e o Feito. Ensaios de Antropologia dos Rituais. Rio de Janeiro: Relume Dumará/NuAP, 2001.

SEGALEN, Martine. Ritos e rituais contemporâneos. Rio de Janeiro: Editora FGV, 2002.

TURNER, Victor W. O processo ritual: estrutura e antiestrutura. Petrópolis: Vozes, 1974.

VAN GENNEP, Arnold. Os ritos de passagem. Petrópolis: Vozes, 1977.

WERNER, Dennis. Uma introdução às culturas humanas: comida, sexo, magia e outros assuntos antropológicos. Petrópolis: Vozes, 1987.

Recebido em 01 de setembro de 2010. Aceito em 07 de fevereiro de 2011. 